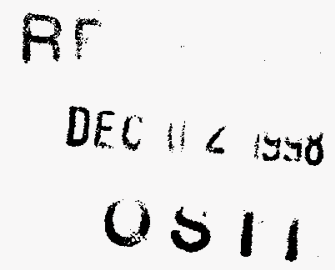

\title{
Task 6.7.3 - Interfacial Mass Transport Effects in Composite Materials
}

\author{
Semi-Annual Report \\ July 1 - December 31, 1997 \\ By: \\ Jan W. Nowok
}

Work Performed Under Contract No.: DE-FC21-93MC30097

For
U.S. Department of Energy
Office of Fossil Energy
Federal Energy Technology Center
P.O. Box 880
Morgantown, West Virginia 26507-0880

By

Energy \& Environmental Research Center

University of North Dakota

P. O. Box 9018

Grand Forks, North Dakota 58202-9018 


\section{DISCLAIMER}

Portions of this document may be illegible in electronic image products. Images are produced from the best available original document. 


\section{DISCLAIMER}

This report was prepared as an account of work sponsored by an agency of the United States Government. Neither the United States Government, nor any agency thereof, nor any of their employees makes any warranty, express or implied, or assumes any legal liability or responsibility for the accuracy, completeness, or usefulness of any information, apparatus, product, or process disclosed or represents that its use would not infringe privately owned rights. Reference herein to any specific commercial product, process, or service by trade name, trademark, manufacturer, or otherwise does not necessarily constitute or imply its endorsement, recommendation, or favoring by the United States Government or any agency thereof. The views and opinions of authors expressed herein do not necessarily state or reflect those of the United States Government or any agency thereof.

Available to the public from the National Technical Information Service, U.S. Department of Commerce, 5285 Port Royal Road, Springfield, VA 22161; phone orders accepted at (703) $487-4650$.

\section{ACKNOWLEDGMENT}

This report was prepared with the support of the U.S. Department of Energy (DOE) Federal Energy Technology Center Cooperative Agreement No. DE-FC21-93MC30097. However, any opinions, findings, conclusions, or recommendations expressed herein are those of the author and do not necessarily reflect the views of DOE.

\section{EERC DISCLAIMER}

LEGAL NOTICE This research report was prepared by the Energy \& Environmental Research Center (EERC), an agency of the University of North Dakota, as an account of work sponsored by the U.S. Department of Energy. Because of the research nature of the work performed, neither the EERC nor any of its employees makes any warranty, express or implied, or assumes any legal liability or responsibility for the accuracy, completeness, or usefulness of any information, apparatus, product, or process disclosed, or represents that its use would not infringe privately owned rights. Reference herein to any specific commercial product, process, or service by trade name, trademark, manufacturer, or otherwise does not necessarily constitute or imply its endorsement or recommendation by the EERC. 


\section{TABLE OF CONTENTS}

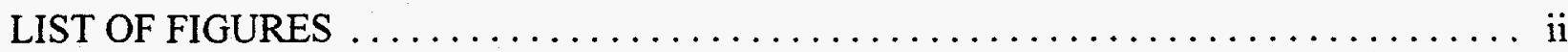

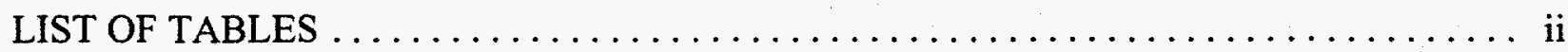

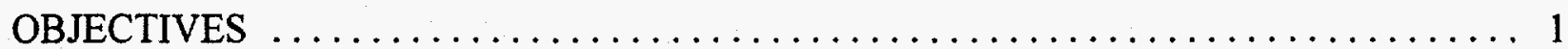

INTRODUCTION $\ldots \ldots \ldots \ldots \ldots \ldots \ldots \ldots \ldots \ldots \ldots \ldots \ldots \ldots \ldots \ldots \ldots \ldots$

LIQUID-SOLID INTERFACES AND APPARENT SURFACE DIFFUSION $\ldots \ldots \ldots \ldots 2$

LAYERING TRANSITIONS AT THE LIQUID-SOLID INTERFACE $\ldots \ldots \ldots \ldots \ldots \ldots 3$

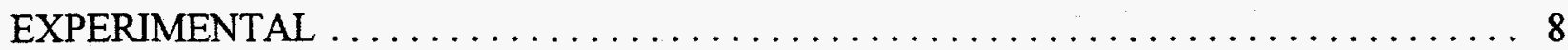

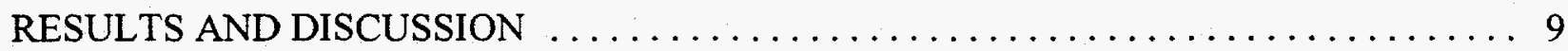

Structural Characterization of $\operatorname{TiN}_{\mathrm{x}}$ and $\operatorname{TiN}_{\mathrm{x}} \mathrm{O}_{\mathrm{y}}$ Thick Films $\ldots \ldots \ldots \ldots \ldots \ldots$

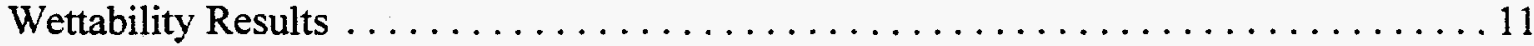

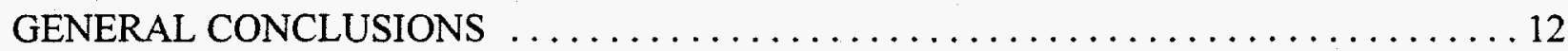

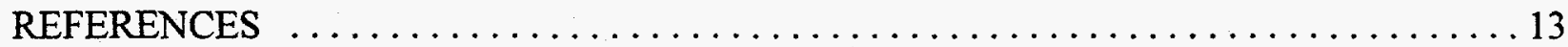




\section{LIST OF FIGURES}

1 Schematic representation of wetting phenomena of liquid metal on a substrate indicating the quasi-solidlike skin formation at the interface

2 The atomic geometry of carbide $(001)$ surface $\ldots \ldots \ldots \ldots \ldots \ldots \ldots \ldots \ldots$

3 ESCA spectra of Ti 2p, N 1s, O 1s, and C 1s obtained from the $\operatorname{TiN}_{x}$ and $\operatorname{TiN}_{x} \mathrm{O}_{y}$

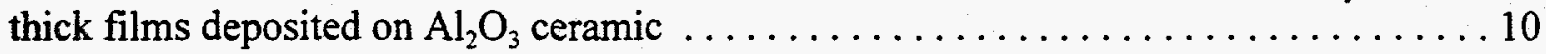

4 ESCA spectra of $\mathrm{N} 1 \mathrm{~s}$ obtained from $\mathrm{TiO}_{1.8} \mathrm{~N}_{0.05}$ (1), $\mathrm{TiO}_{1.9} \mathrm{~N}_{0.13}$ (2), and

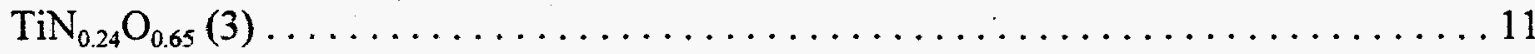

\section{LIST OF TABLES}

1 Contact Angles, Apparent Surface Diffusion Parameters of Liquid Cobalt and Copper, and Work Function for Selected Carbides and Metals ................... 4

2 Electronic Configuration of Outer Shells of the Elements, Number of d Electrons per Atom, Electronic DOS for Selected Liquid Metals, Electron Work Function for Solid Metals, and d-Orbital Energy Level $\ldots \ldots \ldots \ldots \ldots \ldots \ldots \ldots$

3 DOS of Liquid Cobalt and Selected Carbides $\ldots \ldots \ldots \ldots \ldots \ldots \ldots \ldots$

$4 \quad$ DOS and Electrical Resistivity in Selected Nitrides $\ldots \ldots \ldots \ldots \ldots \ldots \ldots \ldots$

5 Contact Angles of Liquid Titanium Determined at 1973K for

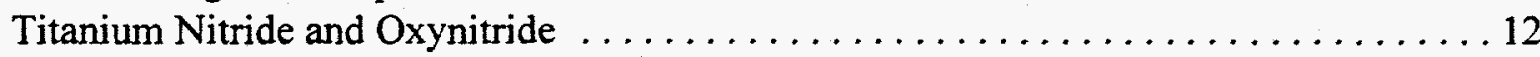




\section{TASK 6.7.3 - INTERFACIAL MASS TRANSPORT EFFECTS IN COMPOSITE MATERIALS}

\section{OBJECTIVES}

Advanced metal-matrix composites (MMCs) consisting of titanium-based alloys possess some unique mechanical, physical, and chemical characteristics that make them highly desirable for aircraft and gas turbine engines. Tailoring MMC properties is essential for advanced product design in materials processing. The main factors that affect materials processing and, further, the nature of a metal-ceramic interface, its structure, and morphological stability is liquid surface mass transport related to adhesional wetting (physical effect) and reactive wetting (chemical effect). ${ }^{1}$

Surfaces and interfaces dominate many of the technologically important processes in composite materials such as liquid-solid sintering and joining. The objective of this work is threefold: 1) to get insight into the role of the nonstoichiometry of chemical composition in ceramic materials used as reinforcement components in MMC processing, 2) to extend previous energetic analysis of mass transport phenomena to wetting behavior between liquid metal and the quasi-solidlike skin resulting from the presolidification of liquid on nonstoichiometric solids on a scale of interatomic distance, and 3) to provide experimental verification of our concept.

\section{INTRODUCTION}

Interfacial mass transport is believed to be controlled by the energetics of wetting driven by capillary imbalance forces rather than the strong layering forces generated by the adsorbed multilayers of a liquid phase on a substrate, ${ }^{2}$ and/or viscoelastic dissipation in the wetting ring of the substrate near the triple point, ${ }^{3}$ and/or alloying either the substrate or adsorbate with other materials. ${ }^{4}$ The strong layering forces seem to depend on changes in the electronic states of the contacting surface layers of both the substrate and the liquid, which can be represented by a work function difference, $\Delta \mathrm{e} \phi$, between liquid and solid (or more rigorously, by the Fermi energy difference) and a difference in the electronic densities of states, $\Delta \mathrm{N}$, at the Fermi level. These parameters are very sensitive to the stoichiometry and composition of the crystalline phase. Induced atomic layering transition to mass transport seems to be a small fraction of the total in solids with a stoichiometric composition; however, it may be large enough to promote mass transport of liquid onto solids with a nonstoichiometric chemical composition such as in carbides and nitrides of transition metals. The objective of this work is to investigate the wetting behavior of nonstoichiometric solids by liquid metals with unfilled d-orbitals. Our concept of the role of nonstoichiometry of composition in surface mass transport was verified by results taken from the literature and by performing wettability tests with liquid titanium on nonstoichiometric $\mathrm{TiN}_{\mathrm{x}}$ and $\mathrm{TiN}_{\mathrm{x}} \mathrm{O}_{y}$ ceramics and correlating those results with the electronic state of ceramics. The presence of gravitational forces that add hydrostatic pressure to wetting is not discussed here. 
The concept of a stratified interface structure is derived from studies on density changes in liquids at free surfaces, premelting of certain crystalline facets, the double-layer structure formed in metal-solvent systems, and the physics of wetting in three-dimensional systems with planar symmetry. ${ }^{5-8}$

\section{LIQUID-SOLID INTERFACES AND APPARENT SURFACE DIFFUSION}

Generally, an ideal metal-ceramic interface should create a good joining to provide mechanical continuity and chemical neutrality to avoid the formation of interphase(s), particularly those with different thermal expansion coefficient(s). At the present, no model is able to satisfactorily describe the processing of MMCs. It is the author's thesis that MMC processing is crucially dependent on surface diffusion in the wetting ring near the triple point, solid-liquid-vapor, and driven by 1) the energetics of wetting: $\gamma_{\mathrm{SV}}-\gamma_{\mathrm{SL}}$ introduced by a liquid metal-substrate interaction (where $\gamma_{\mathrm{Sv}}$ and $\gamma_{\mathrm{SL}}$ represent the solid surface and solid-liquid interfacial energies, respectively), 2) the energetics of wetting arising at the liquid metal-quasisolidlike skin interface (Figure 1, see details below), and 3) the intrinsic stresses at the interface resulting from the formation of the quasi-solidlike skin, which may change the interfacial surface energy of the substrate. The $\gamma_{\mathrm{SL}}$ energy balance suggests that it can either decrease or increase, depending on direct atomic interaction across the interface. For the sake of simplicity, we have chosen to consider the mass transport of liquid on flat surfaces. The role of the shape of substrates such as those present in particles and/or fibers in mass transport is discussed in detail by Cahn and coworkers. ${ }^{9,10}$

In previous work, we attempted to understand the physical and chemical origins of surface mass transport in capillarylike media, metal-metal, and metal-carbide systems. We introduced the apparent surface diffusion parameter given by ${ }^{1}$

$$
D_{\mathrm{S}}+\mathrm{D}_{\mathrm{r}}=\left(\gamma_{\mathrm{Lv}} / \eta\right) L \lambda \cos \theta_{\mathrm{e}} \quad\left[\mathrm{m}^{2} / \mathrm{s}\right] \quad \text { at } \mathrm{T}=\mathrm{constant}
$$

where $D_{S}$ and $D_{r}$ represent diffusion driven by adhesional forces and reaction-enhanced diffusion of atoms from a liquid, respectively; $\gamma_{\mathrm{LV}} / \eta$ is the surface tension-to-viscosity ratio for liquid metal; $\lambda$ is the geometrical factor when anisotropic properties of a substrate result mostly from the roughness of the solid surface; $L$ represents the average atomic/ionic distances in a solid; and $\theta_{\mathrm{e}}$ corresponds to a wettability angle at thermodynamic equilibrium in a liquid-solid system. The equation provides a good estimation of surface diffusion for liquid metal-solid metal systems; however, some large $D_{S}+D_{r}$ values for liquid metals on carbides seem to be suspect and are likely caused by the large difference in $L$ between a solid and liquid (Table 1 ). The $L$ in carbides corresponds to the distance between either carbon or metal atoms in the B1 structure calculated in two crystallographic directions [110] and [100] (Figure 2) and in liquid metals relates to the nearest-neighbor distance. A straightforward strategy to correct the $D_{S}+D_{r}$ property is to assume that the layering transition in liquid metal on a substrate occurs with the formation of the quasisolidlike metal interface. It is expected that the new $\mathrm{L}$ for the quasi-solidlike interface will be between that of a liquid metal and a solid substrate and will not depend on crystallographic

directions. In liquid metal-solid metal systems, the misfit in $\mathrm{L}$ from metal to metal is low; 


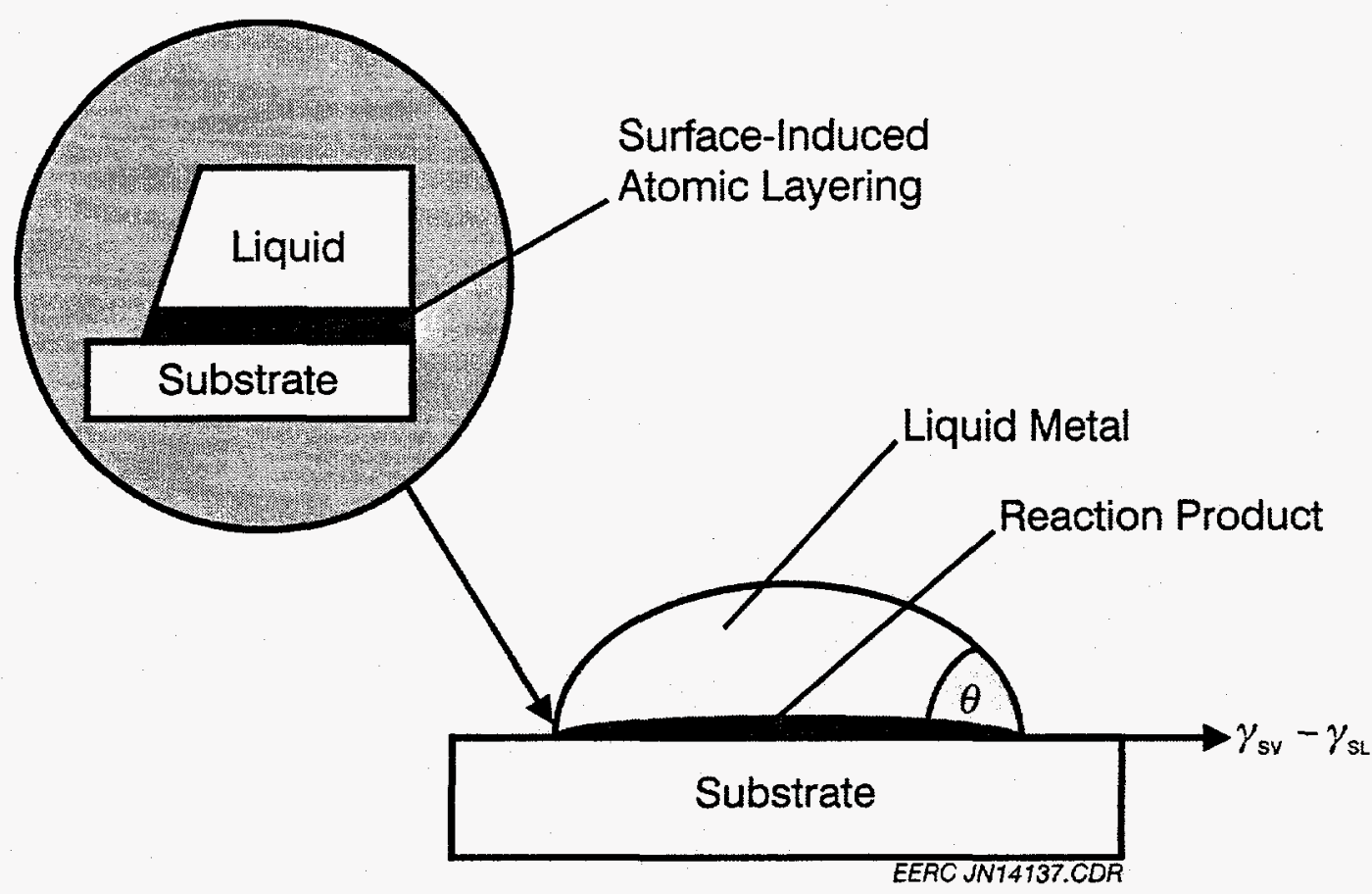

Figure 1. Schematic representation of wetting phenomena of liquid metal on a substrate indicating the quasi-solidlike skin formation at the interface.

however, it is high between metal and oxide/carbide/nitride. Thus, the layering transition at the interface will reduce the misfit between the substrate and liquid phase.

\section{LAYERING TRANSITIONS AT THE LIQUID-SOLID INTERFACE}

To understand the layering transitions at the liquid metal-solid interface generated at the solid-liquid-vapor triple point (Figure 1), one must consider liquid metal structure at melting temperature and the electronic structure of nonstoichiometric ceramics. Liquid metals are considered a two-component fluid, one composed of ion cores and another composed of nearly free s-conduction electrons. The conduction electrons penetrate the ion cores and experience an attractive potential. The characteristic feature of the ion core-electron interaction lies in 1) the ion-electron attractive potential constructed from pseudopotentials and 2) a softness parameter described by a short-ranged repulsive component in the pair potential. Ion-electron forces strongly depend on changing electron density at the Fermi energy level, ${ }^{19}$ and the softness parameter depends on the $s$ and $3 \mathrm{~d}$ electron interaction. Thus, successful determination of the liquid structure of $3 \mathrm{~d}$ transition metals is to define the appropriate effective pair potentials. The $\mathrm{d}$-electron energy in transient metals can be expressed by a tightly bound d-band and a common nearly free-electronlike $s$-band. ${ }^{20}$ The electron bonding term for the liquid transition metals with half-filled and less than half-filled d-bands comes from the strong covalent attractive $\mathrm{s}$ and $\mathrm{d}$ interactions. For systems with a nearly full d-band, s electrons do not contribute to the covalent bonding forces, but to the repulsive interactions. ${ }^{21,22}$ Note that the electronic structure of the 


\section{TABLE 1}

Contact Angles, Apparent Surface Diffusion Parameters of Liquid Cobalt and Copper, and Work Function for Selected Carbides and Metals

\begin{tabular}{|c|c|c|c|c|c|c|c|}
\hline $\begin{array}{l}\text { Liquid } C o \\
\text { and } C u \text { at } \\
T_{m} \text { and } \\
\text { Carbide }\end{array}$ & $\begin{array}{c}\theta_{e} \text { deg } \\
\text { Refs. } 11,12\end{array}$ & $\begin{array}{c}\mathrm{L}(\min ) \\
\mathrm{nm} \\
{[110]}\end{array}$ & $\begin{array}{c}\mathrm{L}(\max ) \\
\mathrm{nm} \\
{[100]} \\
\text { Refs. } 13,14\end{array}$ & $\begin{array}{l}\mathrm{D}_{\mathrm{s}}+\mathrm{D}_{\mathrm{r}} \\
(\mathrm{min}) \\
\mathrm{m}^{2} / \mathrm{s} \\
\times 10^{-8}\end{array}$ & $\begin{array}{l}\mathrm{D}_{\mathrm{s}}+\mathrm{D}_{\mathrm{r}} \\
(\max ) \\
\mathrm{m}^{2} / \mathrm{s} \\
\times 10^{-8}\end{array}$ & $\begin{array}{c}\phi, \mathrm{eV} \\
\text { for clean } \\
\text { surfaces } \\
\mathrm{MC}_{\mathrm{x}}, \mathrm{MN}_{\mathrm{x}} \\
(\mathrm{x}=0.8-1.0) \\
\text { face }(100) \\
\text { Refs. } 15-17\end{array}$ & $\begin{array}{c}\phi, e V \\
\text { at an } \\
\text { exposure } \\
\text { of } 10 \mathrm{~L}^{*} \text { of } \\
\mathrm{O}_{2}, \mathrm{MC}_{\mathrm{x}} \\
(\mathrm{x}=0.8-1.0) \\
\text { face }(100) \\
\text { Ref. } 15\end{array}$ \\
\hline Co Liquid & - & 0.256 & 0.256 & - & - & 5.0 & - \\
\hline $\mathrm{TiC}$ & 30 & 0.308 & 0.437 & 11.8 & 16.6 & 4.1 & 5.8 \\
\hline $\mathrm{ZrC}$ & 35 & 0.334 & 0.472 & 12.1 & 17.0 & 3.5 & 4.7 \\
\hline $\mathrm{HfC}$ & 35 & 0.318 & 0.450 & 11.5 & 16.2 & 4.63 & NA \\
\hline VC & 10 & 0.298 & 0.422 & 13.0 & 18.2 & 4.3 & 5.8 \\
\hline $\mathrm{NbC}$ & 11.5 & 0.319 & 0.449 & 13.8 & 19.3 & 4.1 & 4.6 \\
\hline $\mathrm{TaC}$ & 10 & 0.317 & 0.449 & 13.8 & 19.4 & 4.38 & NA \\
\hline $\mathrm{Cu}$ Liquid & - & 0.257 & 0.257 & & - & 4.7 & \\
\hline $\mathrm{TiC}_{0.98}$ & 110 & 0.308 & - & - & - & & \\
\hline $\mathrm{TiC}_{0.70}$ & 95 & 0.306 & - & - & - & & \\
\hline $\mathrm{TiC}_{0.60}$ & 50 & 0.305 & 0.434 & 6.5 & 9.3 & & \\
\hline $\mathrm{TiC}_{0.50}$ & 5 & 0.304 & 0.433 & 10.1 & 14.4 & & \\
\hline
\end{tabular}

* $1 \mathrm{~L}$ (Langmuir) $=10^{-6}$ torr sec.

liquid metals can be distinctly different from the well-known electronic structure of metallic crystals. ${ }^{23}$

The structure of the stoichiometric cubic refractory transition metal carbides and nitrides consists of a complex combination of localized metal-to-metal and metal-to-nonmetal interactions. In the case of titanium carbide and nitride, the main covalent bonding components in the valence band are mainly formed by 1 ) a strong $2 p-3 d \sigma$ interaction between $C 2 p / N 2 p$ and Ti $3 \mathrm{~d}$ orbitals, and 2) a higher-energy metallic component of $3 \mathrm{~d}-3 \mathrm{~d}$ bonding. Both bands are 


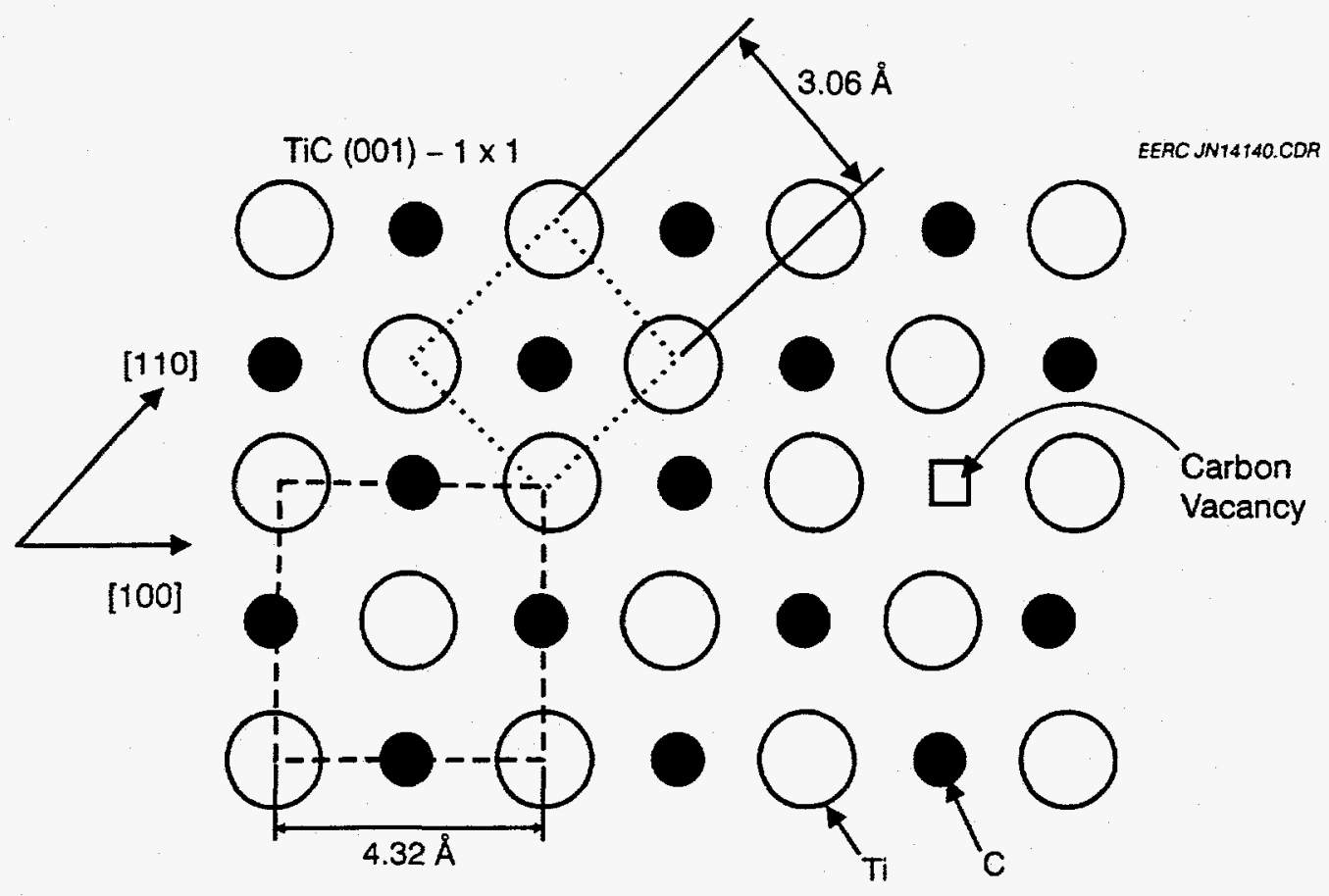

Figure 2. The atomic geometry of carbide (001) surface. ${ }^{18}$

separated by a deep minimum in the density of states. The Fermi energy level lies in the minimum between $2 \mathrm{p}-3 \mathrm{~d}$ and $3 \mathrm{~d}-3 \mathrm{~d}$ bands. ${ }^{24}$ Electrons localized in the $2 \mathrm{p}-3 \mathrm{~d} \sigma$ bands are responsible for cohesion energy, and those localized in the $3 \mathrm{~d}-3 \mathrm{~d}$ band determine electronic properties. ${ }^{25}$ The transition metal carbides and nitrides typically exist as nonstoichiometric with either ordered or disordered vacancies in the nonmetallic sublattice. When carbon/nitrogen vacancies are formed, some charge is transferred to the vacancy sphere from the $C 2 p / N 2 p$ bands and some charge is transferred to both the metal atoms and fills up empty $d$ states and $C / N$ atoms. In the case of titanium carbide and nitride, the s component of the vacancy electronic density of states (DOS) predominates and overlaps with the $3 \mathrm{~d} \mathrm{Ti}$ band. This results in the reduction of covalent bonding and increase of metal-metal bonding and, simultaneously, an increase in the electronic DOS near the Fermi energy level.

Table 2 lists the number of d electrons per atom $\left(\mathrm{N}_{\mathrm{d}}\right)$, the electronic DOS at the Fermi level for several transition liquid metals, and the electron work function for solid metals (e $\phi)$. The corresponding e $\phi$ and DOS for selected refractory transition metal carbides are listed in Tables 1 and 3. Lower $N_{d}$ and DOS values and larger e $\phi$ for liquid metals in relation to those for carbides suggest electron transfer from solid to liquid. The extent of this process depends on the differences in both $\Delta \mathrm{e} \phi$ and DOS between solid and liquid phases. The presence of nonmetal vacancies in carbides/nitrides can control both the electron work function and the electronic DOS (Table 4).

For a description of $3 \mathrm{~d}$ liquid metal-nonstoichiometric carbide (nitride) contact, the nature of the bonding between liquid and solid at the interface must be discussed. A major problem in 


\section{TABLE 2}

Electronic Configuration of Outer Shells of the Elements, Number of d Electrons per Atom, Electronic DOS for Selected Liquid Metals, Electron Work Function for Solid Metals, and d-Orbital Energy Level

\begin{tabular}{|c|c|c|c|c|c|}
\hline Metal & $\begin{array}{c}\text { Electronic } \\
\text { Configuration } \\
\text { of Outer Shells }\end{array}$ & $\begin{array}{c}\text { Number of } \\
\text { d electrons } \\
\text { per Atom, } \mathrm{N}_{\mathrm{d}} \\
\text { Refs. } 20,23\end{array}$ & $\begin{array}{l}\text { DOS at the Fermi } \\
\text { Level for Liquid } \\
\text { Metal, states/eV } \\
\text { per atom } \\
\text { Refs. } 20,23\end{array}$ & $\begin{array}{c}\text { e } \phi \\
\text { for Solid } \\
\text { Metals, } \\
\text { eV } \\
\text { Ref. } 26\end{array}$ & $\begin{array}{l}\text { d-Orbital } \\
\text { Energy Level, } M_{d}, \\
\text { for Liquid Metal, } \\
\qquad \mathrm{eV} \\
\text { Refs. } 27,28\end{array}$ \\
\hline $\mathrm{Ti}$ & $3 d^{2} 4 s^{2}$ & 2.61 & & 4.33 & 2.271 \\
\hline V & $3 d^{3} 4 s^{2}$ & 3.64 & & 4.3 & 1.543 \\
\hline $\mathrm{Cr}$ & $3 d^{5} 4 s^{1}$ & 4.58 & 1.50 & 4.5 & 1.142 \\
\hline $\mathrm{Mn}$ & $3 d^{5} 4 s^{2}$ & 5.57 & 2.34 & 4.1 & 0.957 \\
\hline $\mathrm{Fe}$ & $3 d^{6} 4 s^{2}$ & 6.58 & 2.59 & 4.5 & 0.858 \\
\hline Co & $3 d^{7} 4 s^{2}$ & 7.57 & 2.99 & 5.0 & 0.777 \\
\hline $\mathrm{Ni}$ & $3 d^{8} 4 s^{2}$ & 8.60 & 2.10 & 5.15 & 0.717 \\
\hline
\end{tabular}

TABLE 3

DOS of Liquid Cobalt and Selected Carbides

DOS at the Fermi level, states/eV per atom

\begin{tabular}{ll} 
Liquid Cobalt/Carbide & Ref. 29 \\
\hline Liquid Co & 2.99 \\
TiC & 3.4 \\
$\mathrm{ZrC}$ & 4.5 \\
$\mathrm{HfC}$ & - \\
$\mathrm{VC}$ & - \\
$\mathrm{NbC}$ & 8.3 \\
$\mathrm{TaC}$ & 7.6 \\
\hline
\end{tabular}

describing the electronic structure of an interface and total energy calculations results from the charge transfer consisting of mutually compensating changes in the band energy and in the electronic and exchange correlation contributions caused by the charge redistribution. There seems to be general agreement in the theoretical modeling of liquid-solid interfaces that $\mathrm{s}$ electrons from nonmetallic vacancies in carbides and nitrides cannot be directly involved in the formation of covalent bonds with the $3 \mathrm{~d}$ electrons in $\mathrm{Ti}$ atoms of liquid metal. In fact, the partial delocalization of $\mathrm{s}$ electrons from vacancies on the $3 \mathrm{~d}$ orbitals in Ti atoms of liquid metals 


\section{TABLE 4}

DOS and Electrical Resistivity in Selected Nitrides

\begin{tabular}{lcc}
\hline Carbide & $\begin{array}{c}\text { DOS at } \mathrm{E}_{\mathrm{F}}, \\
\text { states/eV atom } \\
\text { Ref. } 30\end{array}$ & $\begin{array}{c}\text { Electrical Resistivity, } \\
\mu \Omega \mathrm{cm}\end{array}$ \\
\hline $\mathrm{TiC}_{0.95}$ & 3.5 & Ref. 30 \\
$\mathrm{TiC}_{0.92}$ & 4.1 & 145.5 \\
$\mathrm{ZrC}_{0.98}$ & 3.7 & 165.5 \\
$\mathrm{ZrC}_{0.93}$ & 4.8 & 139.7 \\
$\mathrm{ZrC}_{0.93}$ & 5.3 & 180.8 \\
\hline
\end{tabular}

may result from the $3 \mathrm{~d}$ orbitals of $\mathrm{Ti}$ atoms in solid refractory compounds and create covalent $3 \mathrm{~d}$ Ti solid-3d Ti liquid bonds at a heterophase interface.

Generally, the charge density in the center of a nearest-neighbor bond can be considered a measure of bond strength. As the d occupation increases across the $3 \mathrm{~d}$ series of transition metals, the strength of the localized bonds increases (as bonding $d$ states are filled) and then decrease (as the antibonding $\mathrm{d}$ states are filled). In the case of half-filled and less than half-filled $\mathrm{d}$ bands, the covalent bonds should have a rather small effect on the repulsive component in an effective pairwise potential. However, this process may introduce stresses at the interface and change the interfacial surface energy of the solid, which simultaneously may activate surface mass transport of the liquid. ${ }^{10}$ On the other hand, the partial delocalization of s electrons on $3 \mathrm{~d}$-orbitals in liquid metals with a nearly full $d$-band can increase the repulsive term in the $d$ electron energy and the repulsive component in an effective pairwise potential of conduction electrons and ion cores. The decreasing contact angle $\theta$ on nostoichiometric $\mathrm{TiC}_{\mathrm{x}}$ refractory carbide is good evidence of the role of electron transfer from solid to liquid in the wettability process (Table 1 ). The $d \rightarrow s$ transfer of electrons has already been noted in liquid copper, where well-localized d electrons are moved to less localized s-orbitals. According to Koopman's theorem, either the extraction or the addition of one electron into liquid metal may change the energy of all the other electrons and change a Coulomb repulsive component between individual electrons by means of a screened Coulomb interaction. ${ }^{31}$

As a consequence of the partial delocalization of s-conduction nonmetallic vacancy electrons on the ion cores, a close-packed liquid metal layer with higher packing density forms on the substrate, exhibiting a layering transition. This process leads to the ordering of atoms near the interface and a sudden change in melt structure such as observed in a quasi-solidlike skin in a 
solid metal near its premelting temperature. The structure of a thin, coherent phase can be either amorphous or similar to that of a superlattice in alloys. ${ }^{32}$ In this process, a fraction of the full entropy is liberated. It is likely that the ordering mechanism of atoms in a liquid phase at the interface is opposite to the disordering or deconstruction transition in metal crystals below their melting temperature. ${ }^{33-35}$ The existence of layering transitions for metals with low-index faces has already been predicted with density functional calculations. For these systems, the interface states have identical structural parameters. However, at a liquid-solid interface in dissimilar materials, electrons behave as if they belong to two different phases composed of two different structural parameters with some lattice misfit. The misfit energy per unit area of an interface tends to reduce the mismatch of the lattice parameters, depending on bond strength, interlayer thickness, and the elastic properties of the substrate. The lattice misfit may introduce stresses and structural defects.

The formed quasi-solidlike skin can support a potential difference, but will be transparent to the flow of electrons between the liquid metal and substrate such as in a metal-semiconductor junction with an interfacial layer. The quasi-solidlike skin may reduce the e $\phi$ of a substrate. It has already been demonstrated that the work function of $\alpha-\mathrm{SiC}$ can be reduced from 4.5 to $2.9 \mathrm{eV}$ when the thickness of deposited europium increases from 0 to $20 \AA . .{ }^{36}$ Electron work functions usually decrease as temperature rises, mainly as a result of lowering the material's density. Unfortunately, no measured values for work functions in liquid metals, except for alkalies, are available in the literature. Therefore, in this discussion, values of e $\phi$ determined for solid phases are used. Generally, work function is highly sensitive to perturbation at a material's surface resulting from crystallographic orientation, nonstoichiometry, and adsorption of gases.

The increase in work function in carbides with oxygen content (Table 1) creates new energies in the surface state, which in particular cases may reduce the probability of layering transitions and, simultaneously, of the wetting ability of oxidized carbides. Usually, oxygen atoms occupy carbon/nitrogen vacancies, increasing the ionic character of the bonds.

\section{EXPERIMENTAL}

A series of $\operatorname{TiN}_{x}$ and $\operatorname{TiN}_{x} \mathrm{O}_{y}$ films formed from a TiCl $4, \mathrm{~N}_{2}, \mathrm{H}_{2}$, and $\left(\mathrm{N}_{2}+\mathrm{O}_{2}\right)$ gas mixture was deposited on alumina ceramics at $1073 \mathrm{~K}$ for $5 \mathrm{hr}$ at atmospheric pressure, according to the procedure described in Dekker et al. ${ }^{37}$ These conditions were selected because they offer a reasonable deposition rate and low chlorine content in films. The $\mathrm{TiN}_{\mathrm{x}}$ films, with two different nonstoichiometries controlled by the ratio of $\mathrm{N}_{2}$ to $\mathrm{H}_{2}$, and two $\operatorname{TiN}_{\mathrm{x}} \mathrm{O}_{\mathrm{y}}$ films, with different nitrogen and oxygen content, were prepared. The $\mathrm{N}_{2}$ and $\mathrm{H}_{2}$ gases were first purified in alkaline pyrogallol and dried over silica gel and further over a copper and palladium catalyst. The $\mathrm{TiCl}_{4}$ concentration in flowing $\mathrm{N}_{2}$ and $\mathrm{H}_{2}(70 / 30)$ corresponded to its vapor pressure over liquid at $300 \mathrm{~K}$. The film thicknesses were determined using a multiple interferometer. All of the films obtained were thicker than $100 \mathrm{~nm}$. Crystalline phases are determined by $\mathrm{x}$-ray diffraction analysis at room temperature. The size of titanium nitride grains was between 1 and $3 \mathrm{~m} \mu$. The films were characterized by electron spectroscopy for chemical analysis (ESCA) using a PHI 595 multiprobe for depth profiling. $\mathrm{A} \mathrm{Mg} \mathrm{K} \alpha \mathrm{x}$-ray source and a double-pass cylinder mirror electron 
analyzer were used for excitation. Peak positions were corrected by assuming that the very weak $\mathrm{C} 1 \mathrm{~s}$ photoelectron line present.for each sample was at $284.6 \mathrm{eV}$. The analysis area was $0.8 \mathrm{~mm}$ in diameter and $30 \AA$ deep. All measurements were taken at room temperature.

Wettability tests of liquid titanium on $\operatorname{TiN}_{x}$ and $\operatorname{TiN}_{x} \mathrm{O}_{y}$ films were done using the sessile drop technique in high-purity $\mathrm{Ar}$ at $1973 \mathrm{~K}$.

\section{RESULTS AND DISCUSSION}

\section{Structural Characterization of $\operatorname{TiN}_{x}$ and $\operatorname{TiN}_{x} \mathrm{O}_{y}$ Thick Films}

$\mathrm{X}$-ray structural analysis showed that $\mathrm{TiN}_{\mathrm{x}}$ thick films crystallized in cubic $\mathrm{B} 1$ structure. There is a characteristic trend in changes of the lattice parameter for $\operatorname{TiN}_{x}$, which decreases from $0.4240 \pm 0.0003$ to $0.4225 \pm 0.0002 \mathrm{~nm}$ with a nitrogen content deficit. The lattice parameter decrease results from the formation of nitrogen vacancies. ${ }^{38}$ The presence of a high number of vacancies in the lattice can lead to an anisotropic distortion of the crystalline lattice. The lattice distortion cannot be exactly cubic, but can be represented by a rhombohedral cell with a rhombohedral angle of about $89.5^{\circ} . .^{39}$ The anisotropic distortion of the crystalline lattice is usually seen in $\mathrm{TiN}_{\mathrm{x}}$ films grown below $673 \mathrm{~K}$. In this case, we did not observe distortion of the TiN crystalline lattice, since $\mathrm{TiN}_{\mathrm{x}}$ films were deposited at $1073 \mathrm{~K}$, which means at a temperature high enough above the relaxation temperature of the lattice, $673 \mathrm{~K}$.

$\mathrm{XRD}$ results of the $\operatorname{TiN}_{\mathrm{x}} \mathrm{O}_{\mathrm{y}}$ samples with oxygen content about $\mathrm{x}=0.18$ showed the presence of weak peaks belonging to the $\mathrm{TiO}$ phase; those with high oxygen content, above $\mathrm{x}=$ 0.65 , indicated peaks pertaining to the $\mathrm{TiO}_{2}$ phase. Generally, the substitution of oxygen atoms for nitrogen in $\mathrm{TiN}_{\mathrm{x}}$ results in a decrease in the lattice parameters and the formation of an amorphous phase ${ }^{40}$ This $\mathrm{TiN}_{\mathrm{x}} \mathrm{O}_{\mathrm{y}}$ phase can be unstable if exposed to an oxygen atmosphere and may gradually decompose to $\mathrm{TiO}_{2}$ and nitrogen. The nitrogen molecules can remain in the interstitial positions of the surface oxide layers below $673 \mathrm{~K}$.

Detailed structural information about $\operatorname{TiN}_{x}$ and $\operatorname{TiN}_{x} \mathrm{O}_{y}$ films was obtained from ESCA tests. Figure 3 illustrates ESCA spectra for the Ti 2p, O 1s, N 1s, and C 1s (as reference) peaks in selected $\mathrm{TiN}_{\mathrm{x}}$ and $\mathrm{TiN}_{\mathrm{x}} \mathrm{O}_{\mathrm{y}}$ specimens. The peaks at about 456 and $462 \mathrm{eV}$ can be assigned to $\mathrm{Ti}$ $2 \mathrm{p}$ in nonstoichiometric titanium nitride, and at about 458 and $464 \mathrm{eV}$ that can be assigned to $\mathrm{Ti}$ $2 \mathrm{p}$ in nonstoichiometric titanium oxide with a partially ionic Ti-O bond. The partially ionic character of the valence electrons in the Ti-X bond (where $\mathrm{X}$ represents nonmetal) is usually observed in the progressive decrease in the refractory character of titanium compounds from TiC through TiN to TiO. ${ }^{41}$ All recorded titanium ESCA spectra show features of both the Ti $2 \mathrm{p}_{3 / 2}$ and Ti $2 \mathrm{p}_{1 / 2}$ transitions. The ESCA spectra of $\mathrm{N} 1 \mathrm{~s}$ in $\mathrm{TiN}_{0.24} \mathrm{O}_{0.65}$ specimens show two distinctive peaks with different binding energies. The peaks at about $397 \mathrm{eV}$ and $401 \mathrm{eV}$ correspond to the nitrogen states hybridized to Ti $3 \mathrm{~d}$ orbitals in Ti-N covalent bonding. ${ }^{42}$ The second peak at about $401 \mathrm{eV}$ may be assigned to nitrogen atoms with a partially ionic character as observed in oxynitride. ${ }^{42,43}$ The partially ionic character of nitrogen atoms comes from their ability to donate 

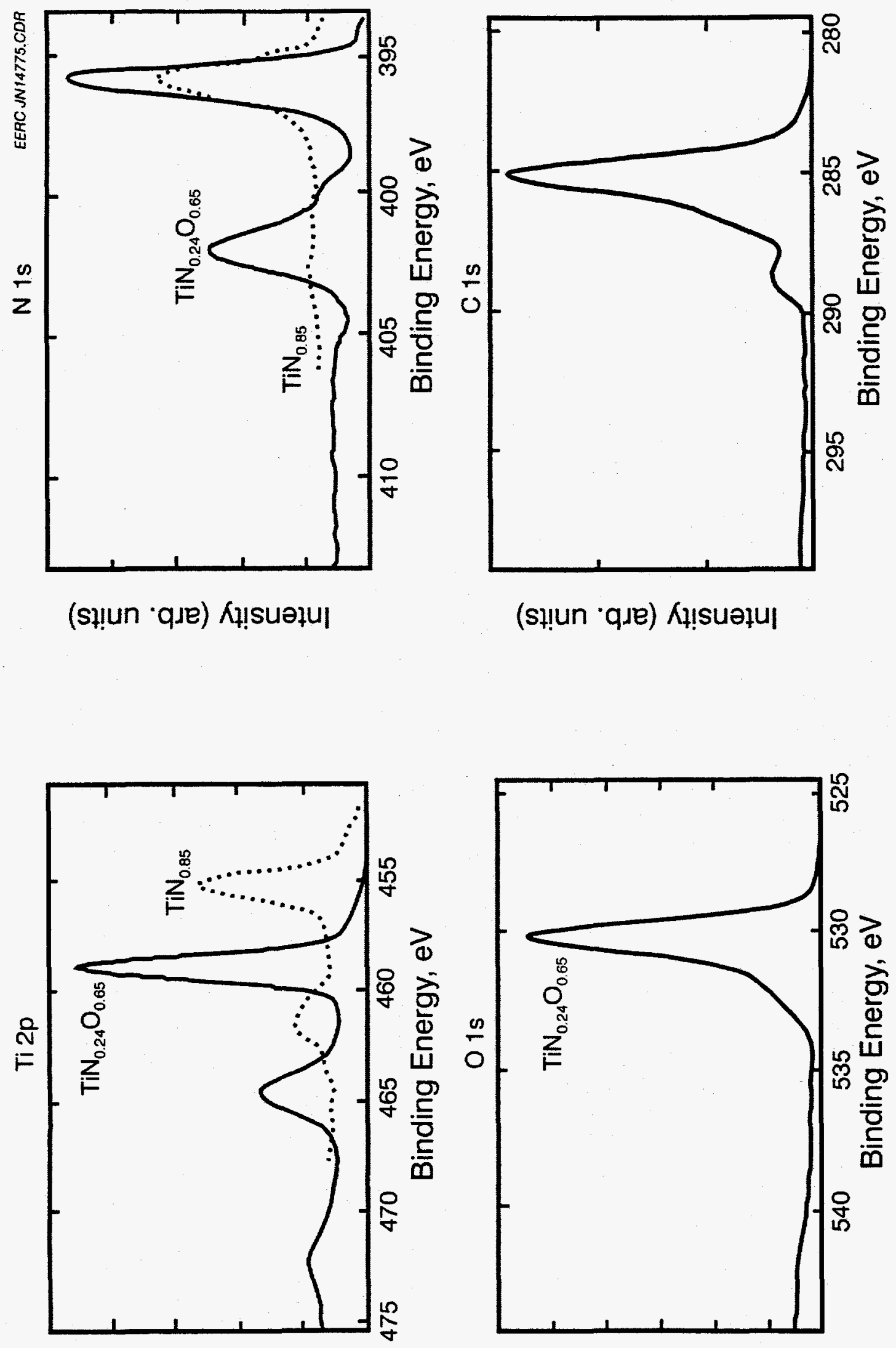

(st!un que) אł!suәłul

(sł!un 'que) Ki!suəłu! 
electrons to $\mathrm{O}$ atoms, $\mathrm{N} \rightarrow \mathrm{O}$, which depends on the nature of the metal in the crystal lattice. The occurrence of a small satellite at a shoulder toward lower binding energy (about $400 \mathrm{eV}$ ) may belong to the interstitial molecular nitrogen. A similar satellite peak is detected near the $O 1 \mathrm{~s}$ peak at the shoulder toward higher binding energy (about $532 \mathrm{eV}$ ), which can indicate adsorbed oxygen. ${ }^{43}$

It is expected that the charge transfer from oxygen vacancies to oxygen in an $\mathrm{N}-\mathrm{O}$ bond should cause the chemical shift of the $\mathrm{N} 1 \mathrm{~s}$ peak toward higher binding energy and simulate the creation of a new peak in the $\mathrm{NO}_{\mathrm{x}}$ cluster with a new oxidation state. In order to verify this hypothesis, we prepared two nonstoichiometric $\mathrm{TiO}_{2}$ films with low nitrogen content at $1073 \mathrm{~K}$ using the chemical vapor deposition technique described in the previous section. Figure 4 illustrates the variation of nitrogen-binding energy in three titanium-rich oxide films. The peak positions of $\mathrm{N} 1 \mathrm{~s}$ are strongly dependent upon the oxygen content in titanium oxide. These suggest that nitrogen polarity may predominantly depend on both the oxygen and vacancies content in oxynitride. The formation of another oxynitride intermediate phase and/or $\mathrm{NO}_{\mathrm{x}}$ rather than $\mathrm{N}-\mathrm{O}$ coupling with nonmetallic vacancies is unknown in the literature. However, electrons associated with vacancies can be pulled down by oxygen atoms, causing the rearrangement of valence electrons in nitrogen atoms.

\section{Wettability Results}

Table 5 lists the measured contact angles of liquid titanium on $\operatorname{TiN}_{\mathrm{x}}$ and $\operatorname{TiN}_{\mathrm{x}} \mathrm{O}_{\mathrm{y}}$ films at 1973K. The value of contact angles significantly depends on the stoichiometry and composition

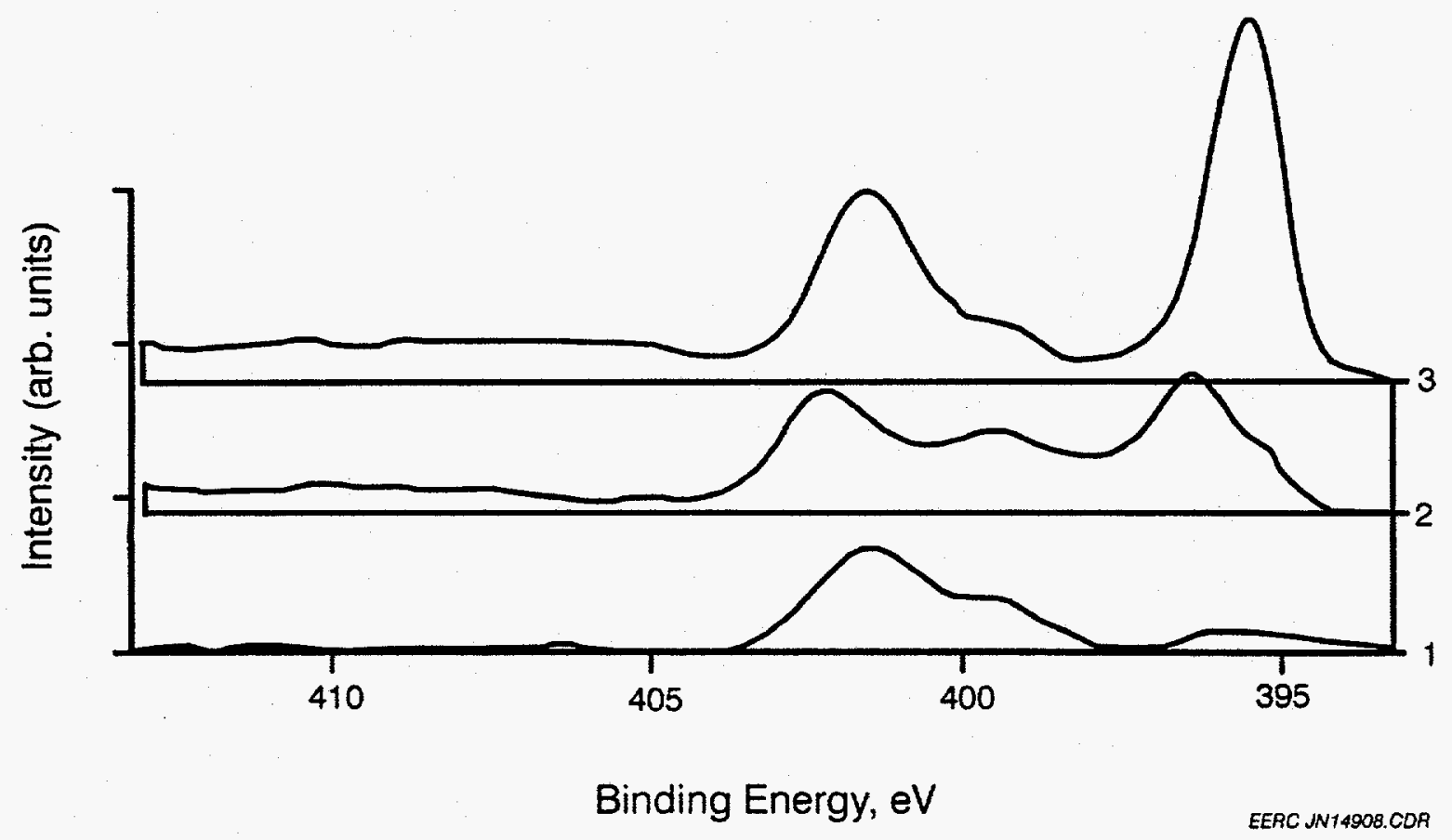

Figure 4. ESCA spectra of $\mathrm{N} 1 \mathrm{~s}$ obtained from $\mathrm{TiO}_{1.8} \mathrm{~N}_{0.05}(1), \mathrm{TiO}_{1.9} \mathrm{~N}_{0.13}(2)$, and

$$
\operatorname{TiN}_{0.24} \mathrm{O}_{0.65}(3) \text {. }
$$


of the titanium nitride. The nitrogen vacancies reduce contact angles, and oxygen impurities increase the $\theta_{\mathrm{e}}$. These results are consistent with our model, which suggests that both lower work function and higher electron density in $\mathrm{TiN}_{\mathrm{x}}$ ceramics, in comparison to those in liquid titanium, may activate the formation of a quasi-solidlike metallic interface which, in turn, should generate the electrical double layer and finally promote mass transport of the liquid metal. On the other hand, contaminants such as oxygen both increase the work function and decrease the electronic DOS at the Fermi level of $\operatorname{TiN}_{\mathrm{x}}$ ceramics to a value close to that of the work function of titanium metal, which simultaneously causes a decrease in the mass transport process. The weakening of adhesion properties in $\mathrm{TiN}_{\mathrm{x}} \mathrm{O}_{\mathrm{y}}$ films deposited on a Ti substrate reported in the literature has been assigned to stresses generated at the interface at the time. ${ }^{45}$

\section{TABLE 5}

Contact Angles of Liquid Titanium Determined at 1973K for Titanium Nitride and Oxynitride

\begin{tabular}{lcc}
\hline & & Sample/e $\phi, \mathrm{eV}$ \\
Nitride & $\theta_{\mathrm{e}}, \mathrm{deg}$ & Ref. 44 \\
\hline Ti solid & - & 4.3 \\
$\mathrm{TiN}_{0.96}$ & 22 & $\mathrm{TiN}_{0.99} / \mathrm{e} \phi=3.79$ \\
$\mathrm{TiN}_{0.85}$ & 15 & $\mathrm{TiN}_{0.80} / \mathrm{e} \phi=3.66$ \\
$\mathrm{TiN}_{0.75} \mathrm{O}_{0.08}$ & 35 & \\
$\mathrm{TiN}_{0.60} \mathrm{O}_{0.18}$ & 38 & \\
\hline
\end{tabular}

The above results suggest that in investigating the liquid metal wetting phenomenon, the electronic component generated at the metal-substrate interface must not be neglected. Its physical origins result from the difference in both the electron work function and the DOS. Surface mass transport at the triple point (solid-liquid-vapor) may proceed by the lateral diffusion of atoms on the quasi-solidlike skin driven by the energetics of wetting and stresses resulting from the strong attractive interactions arising from $3 \mathrm{~d} \mathrm{Ti}$ (solid)-3d Ti (liquid) covalent bonding at the interface supported by $s$ electrons from nitride vacancies.

\section{GENERAL CONCLUSIONS}

This is a broad discussion of metallic interfaces on nonstoichiometric refractory transition metal carbides/nitrides to indicate the significance of the electronic effect in the fabrication of 
metal-matrix composites. Knowledge of the electronic structures of interfaces should give insight to the work of adhesion, and indirectly, the mechanical properties of interfaces. Generally, the work of adhesion correlates with the brittle fracture of the metal-ceramic interface. ${ }^{46}$ Its strong bonding is manifested in high elastic constants and its hardness. In the case of less than halffilled d-bands in liquid metals such as titanium, the metallic interfaces on nonstoichiometric ceramics may create strong covalent $\mathrm{V}_{s}{ }^{\mathrm{n}}-3 \mathrm{dTi}$ (solid)-3d Ti (liquid) electron bonding, which may generate stresses in the quasi-solidlike skin, where $V_{S}$ represents a nitrogen vacancy with a charge $n-$. Oxygen in titanium nitride reduces the interfacial electron charge accumulation at the interface, which may weaken the adhesive bonding between metal and substrate..$^{47,48}$ Therefore, the interplay between nonstoichiometry and oxygen content in titanium carbide/nitride may allow the modeling of interfacial mechanical properties from brittle to semibrittle and/or to ductile.

\section{REFERENCES}

1. J.W. Nowok, Mater. Sci. Eng. A232, 157 (1997).

2. A.A. Cernov and L.V. Mikheev, Phys. Lett. 60, 2488 (1988); Physica A157, 1042 (1989).

3. A. Carre, J-C. Gastel and M.E.R. Shanahan, Nature 379, 432 (1996).

4. R.M. Cannon, E. Saiz, A.P. Tomsia and W.C. Carter, Met. Res. Soc. Symp. Proc. 357, 279 (1995).

5. M. Hasegawa and T. Ichikawa, J. Phys: Condens. Matter 3, 2769 (1991).

6. M.J. Regan, E.H. Kawamoto, S. Lee, P.S. Pershan, N. Maskil, M. Deutsch, O.M. Magnussen and B.M. Ocko, Phys. Rev. Letters 75, 2498 (1995).

7. L. Bosio, R. Cortes, G. Folcher and M. Froment, J. Electrochem. Soc. 139, 2110 (1992).

8. J.R. Henderson, Phys. Rev. E50, 4836 (1994).

9. J. W. Cahn and J.E. Taylor, Acta Metall. Mater. 42, 1045 (1994).

10. W.C. Carter, A.R. Roosen, J.W. Cahn and J.E Taylor, Acta Metall. Mater. 43, 4309 (1995)

11. R. Warren, J. Mater. Sci. 15, 2489 (1980).

12. R. Standing and M. Nicholas, J. Mater. Sci. 13, 1509 (1978).

13. J. W. Nowok, Acta Metall. Mater. 42, 4025 (1994). 
14. V. Moisy-Maurice, N. Lorenzelli, C.H. de Novion and P. Convert, Acta Metall. 30, 1769 (1982).

15. P.A.P Lindberg and L.I. Johansson, Surf. Sci. 194, 199 (1988).

16. G.R. Gruzalski, S.C. Lui and D.M. Zechner, Surf. Sci. 239, L517 (1990).

17. M. Weiner and R.E. Watson, Phys. Rev. B29, 3001 (1984).

18. M. Aono, Y. Hou, R. Souda, C. Oshima, S. Otani and Y. Ishizawa. Phys. Rev. Letters 50, $1293(1983)$.

19. N. Matsuda, H. Mori, K. Hoshino and M. Watabe, J. Phys. (Condensed Matter) 3, 827 (1991).

20. W. Jank, Ch. Hausleitner and J. Hafner, J. Phys: Condens. Matter 3, 4477 (1991).

21. Ch. Hausleitner, G Kahl and J. Hafner, J. Phys: Condens. Matter 3, 1589 (1991).

22. Ch. Hausleitner and J. Hafner, Phys. Rev. B47, 5689 (1993).

23. J. Hafner and W. Jank, Phys. Rev. B42, 11530 (1990).

24. J. Ridinger, R. Eibler, P. Herzig, A. Neckel, R. Podloucky and E. Wimmer, J. Phys. Chem. Solids, 46, 383 (1985).

25. L.M. Huisman, A.E. Carlsson, C.D. Gelatt, Jr. and H. Ehrenreich, Phys. Rev. B22, 991 (1980).

26. CRC Handbook of Chemistry and Physics (Editor R.C. Weast), Boca Raton, 1989, p. E91.

27. M. Morinaga, N. Yukawa and H. Adachi, J. Phys. Soc. Jpn. 53, 653 (1984).

28. K. Matsugi, Y. Murata, M. Mirinaga and N. Yukawa, in Superalloys 1992 (Editors S.D. Antolovich, R.W. Stusrud, R.A. MacKay, D.L. Anton, T. Khan, R.D. Kissinger, D.L. Klastrom), The Minerals, Metals \& Materials Society, 1992, p. 307.

29. B.M. Klein, D.A. Papaconstantopoulos and L.L. Boyer, Phys. Rev. B22, 1946 (1980).

30. F.A. Modine, M.D. Foegelle, C.B. Finch and C.Y. Allison, Phys. Rev. B40, 9558 (1989).

31. T.E. Faber, Introduction to the Theory of Liquid Metals, Cambridge, University Press, 1972.

32. S.P. Phillpot, D. Wolf and S. Yip, MRS Bulletin 15, 38 (1990). 
33. G. Bilalbegovic and E. Tosatti, Phys. Rev. B48, 11240 (1993).

34. H. Hakkinen and M. Manninen, Phys. Rev. B46, 1725 (1992).

35. F. Ercolessi, S. Iarloi, O. Tomagnini, E. Tosatti and X.J. Chen, Surf. Sci. 252/252, 645 (1991).

36. S. Kennou, J. Appl. Phys. 78, 587 (1995).

37. J.P. Dekker, P.J. van der Put, H.J. Veringa and J. Schoonman, J. Electrochem. Soc. 141, 787 (1994).

38. L. Mirenghi, M.A. Baker, A. Rozzi, R. Bertoncello and P. Rotolo, Proc. ECASIA '95, J. Willey, Chichester, 1996, pp. 883-886.

39. F. Elstner, A. Enrlich, H. Giegengack, H. Kupfer and F. Richter, J. Vac. Sci. Technol. A12, $476(1994)$.

40. P. Jin and S. Maruno, Jpn. J. Appl. Phys. 30, 2058 (1991).

41. S.P. Denker, J. Less-Common Met. 14, 1 (1968).

42. P. Prieto and R.E. Kirby, J. Vac. Sci. Technol. A13, 2819 (1995).

43. F. Esaka, K. Furuya, H. Shimada, M. Imamura, N. Matsubayashi, H. Sata, A. Nishijima and T. Kikuchi, J. Vac. Sci. Technol. A15, 2521 (1997).

44. H. Hoschst, R.D. Bringas, P. Steiner and Th. Wolf, Phys. Rev. Letters 50, 7183 (1982).

45. M. Alvisi, A. Rizzo, L. Tapfer and L. Vasanelli, Thin Solid Films 298, 130 (1997).

46. F. Ernst, Mater. Sci. Engin. R14, 97 (1995).

47. T. Hong, J.R. Smith and D.J. Srolovitz, Phys. Rev. B47, 13615 (1993).

48. T. Hong, J.R. Smith and D.J. Srolovitz, Acta Metall. Mater. 43, 2721 (1995). 